\title{
Shipbuilding Product Development using War Room Marketing Analysis
}

\author{
A. Aris Wacana Putra ${ }^{1, a}$, Ivan Kristianto Singgih ${ }^{2,3, b, *}$, Defi Norita ${ }^{4,5, c}$, Putri Dyah Setyorini ${ }^{6, d}$ \\ and A. A. B. Dinariyana ${ }^{6, e}$ \\ ${ }^{1}$ Naval Ship Division, PT. PAL Indonesia, Surabaya, Indonesia \\ ${ }^{2}$ Department of Industrial Engineering, Sepuluh Nopember Institute of Technology, Surabaya, \\ Indonesia \\ ${ }^{3}$ Department of Industrial and Management Engineering, Pohang University of Science and \\ Technology, Pohang, South Korea \\ ${ }^{4}$ Department of Industrial Engineering, Mercubuana University, Jakarta, Indonesia \\ ${ }^{5}$ Department of Agroindustrial Technology, Bogor Agricultural University, Bogor, Indonesia \\ ${ }^{6}$ Department of Marine Engineering, Sepuluh Nopember Institute of Technology \\ Surabaya, Indonesia \\ a.ariswp@gmail.com,b.ivanksinggih@postech.ac.kr,c.defi.norita@gmail.com, \\ d.putridyahs@gmail.com,e.kojex@its.ac.id \\ *ivanksinggih@postech.ac.kr
}

Keywords: Marketing Strategy, Mathematical Model, Product Development, Shipbuilding, War Room

Abstract: War room strategy is used to assess the effectiveness of marketing strategies in companies. In this study, important aspects of shipbuilding products from customer point of view are addressed. Moreover, a method to select marketing strategies, which are appropriate to improve the product aspects are proposed. During the development, the product's competitiveness must be assured. Thus, the product's aspects must be compared with its competitors and the comparison must be used as basis for improving the product's aspects using the marketing strategies. A set of existing marketing strategies, their effects to improve each product aspect, and limited resources for the improvement are considered. Some mathematical models are proposed to select the best marketing and product development strategies. The models represent the product development problem from various points of view, which are shown by the difference in models' objectives, constraints, and decision variables. The conformance of each model to deal with various situations is discussed.

\section{Introduction}

More intense competition becomes a threat for the existence of a company in shipbuilding industry. Competitiveness in shipbuilding industry has been stated in [1] as 'the ability to win and execute shipbuilding orders in open competition and stay in business'. The fierce competition can be 
understood from the difficulty to obtain an order from the customer. This situation encourages each company to continuously improve its business strategies. Among them, marketing and product development strategies for ship and non-ship product are important aspects to be dealt with.

In order to select the appropriate selling strategy, a company needs to identify its strength and understand its weakness, while analyzing customer's behaviors. The strategy must be selected based on the company's assessed competitive advantages, which can assist the company to satisfy customer requirements.

Reduction of global oil price in previous years caused the companies to restrict their production level improvement and postpone their business expansion. In addition, it forced the companies to layoff their employees and receive less orders from oil and gas companies. Meanwhile, some global issues such as safety issues, Brexit, monetary issues in East Asian countries, etc, also affect global economy and must be analyzed well. The bankruptcy of some big shipping companies may be one of some possible effects. This situation causes difficulties in economic growth and could highly influence customer's buying behavior and eventually the company's profit.

A war room concept is used to analyze, develop, and determine the appropriate strategy, which is suitable with the company's values. In order to perform the analysis, the required data are obtained from market research, customer satisfaction surveys, expert and management recommendations, and company's business plans [2]. In the war room concept, a very focused and intense discussions are conducted to visualize the data and identify linkages between various information and plans [3]. The obtained data are organized and used to assess product performance. War room strategy can be implemented in a low-tech approach using boards, or even in high-tech rooms, where computer generated information are utilized [3].

The main focus of the development in the war room strategy must be the customer satisfaction. Regardless of any business type, improving and maintaining customer satisfaction affects the number of sales and assure the continuity of the business. The satisfaction itself can be influenced by various product aspects, which may be low prices that is suitable for most customers, or even good products and services for customers with higher buying capacity. Using the war room strategy, the importance of the product value are measured and appropriate strategies to be taken, are analyzed and selected.

An example of a war room strategy is shown in [4], in which a group of sales are gathered and given a mandate to perform sales decisions during several months. The members of the war room team meet every week to perform analysis and update the latest reports. This team also has an access to senior executives, which allow them to alert the executives about important issues related with new product and service packages. The war room strategy enables the company to identify important issues through data analysis performed by a team that discusses frequently, while taking effective decisions to solve those issues well.

War room strategy enables the company to identify actual problems because of utilizing real information as input for the analysis [5]. Thus, it leads to a deeper insight about marketing decision performances and budgeting exercises. In addition, frequent and deep discussions performed by these experts may allow identifying actual problems faster and more effectively than general marketing planning, which are performed in a less frequent manner. Differences between the war room with other strategies are discussed more in [6]. The war room concept is used as a new analysis method by organizing two leaders of cooperating companies to perform intensive discussions to solve some unresolved issues in a project. After using the war room strategy, it was proven that more effective communication occur and leads to a better decision making compared with the previous analysis method, in which decisions are made more decentralized with lack of communication intensity. 
In this study, important aspects of ship product and non-product are listed, marketing strategies are introduced, and method used to select the appropriate strategy for a company is developed. The listed aspects and proposed methodology are useful for developing an effective strategy in the war room marketing approach.

This study is presented as follows: in the next section, possible targets of a shipbuilding company are defined. Section 3 introduces a framework that explain how shipbuilding products must to be improved from the view point of existing parties in the supply chain. Section 4 provides the list of possible marketing and product development strategies. Section 5 presented some mathematical models, which are used for selecting the best strategy to achieve company's target. Section 6 concludes the study.

\section{Targets of Shipbuilding Industries}

Each shipbuilding company may set its own target for attracting customers, e.g. high quality or low cost. Due to the limited resources, in order to improve a certain product aspect, it may be necessary to sacrifice some other aspects [2].

Some aspects of shipbuilding products, which are considered important by the customers, are as follows:

1. Capacity

2. Delivery time, in order to deal with the new developments of yards and docks [7]

3. Price

4. Quality

5. Possible customization level

6. Updated service status during the shipbuilding process

A model used to identify product competitive aspects and their relative importance were proposed in [1]. Instead of the price, a profit comparison indicator was introduced, which was calculated based on the price and the required unit shipbuilding cost.

\section{Product Competition Environment}

\subsection{Related Parties}

Based on analysis in [7], some factors affecting the competitiveness of a shipbuilding industry are industry structure and competitive environment. The industry structure is related with the following industry capabilities: access to raw materials, labor and skills, knowledge and technology, capital, etc. Competitive analysis itself can be performed in supply (product and service providers) and demand side (customer). In other words, the marketing strategies may be effective to increase the customer satisfaction and demand levels, while the product development strategies are proposed in order to improve product aspects that are measured relatively to the company's competitors. Both types of strategies are executed in order to improve a set of product aspects considering their relative importance levels. Both marketing and product development strategies must be executed well simultaneously in order to offer some innovative marketing plans for the customers.

\subsection{Comparison with Competitors}

Shipbuilding products must be developed effectively. In other words, the developments must assure an increase in customer's satisfaction and demand level. The shipbuilding product quality may be evaluated based on comparison with customer requests or the previously produced quality. However, it is more important to evaluate the current shipbuilding product qualities relative to other 
shipbuilding manufacturers' products. In other words, it is necessary to assess the relative capability of the shipbuilding company to satisfy customer demands while comparing the capability with its competitors. This relative assessment becomes more important in a situation where the current shipbuilding manufacturer cannot provide the best qualities in all product aspects.

Porter's 5 forces shows important factors affecting the competition. The rivalry between the existing competitors and threat from new competitors are included as two of those forces. It is mentioned in [8] that if the forces are strong, the competition is hard and it may be difficult to gain profit. Some strategies used to deal with the entrance of new competitors aim to reduce the prices and costs and avoid the competitor gaining more market share.

Some tools used for visually presenting the comparisons are presented in [2], such as bubble chart option, which shows the relative size of different suppliers in the market, and attribute plot that compares the current scores with another competitor on important aspects of the product. Figure 1 shows the example of the tools.
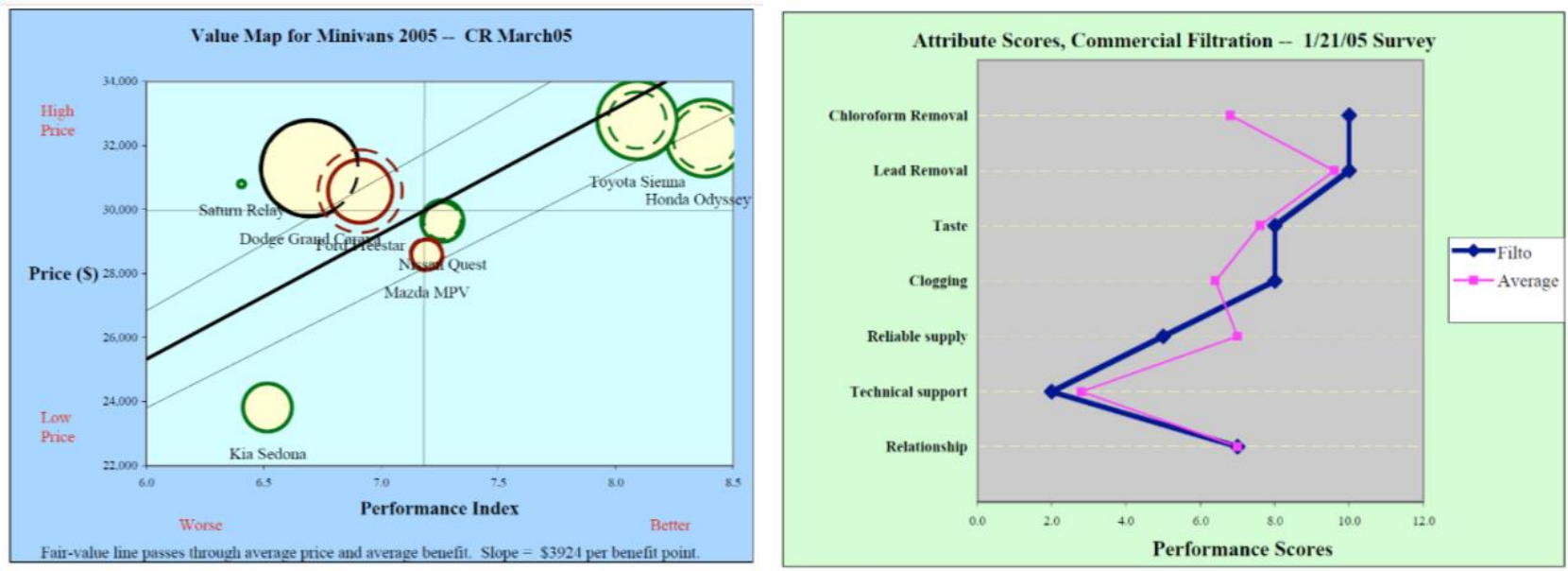

Figure 1: Example of bubble chart (left) and attribute plot (right) [2]

\section{Marketing and Product Development Strategies}

\subsection{Marketing Strategies}

In order to improve the product aspects, some marketing strategies were proposed in [2] as follows:

- Product introductions

- Advertisements

- Segmentation and differentiation projects, which may be related with new ship design process

- Pricing

The shipbuilding manufacturers' past experiences with the customer may be an important factor to determine the price [1]. Thus, developing appropriate contract schemes can be another good marketing strategy.

\subsection{Product Development Strategies}

In [2] and [7], the following product development strategies are listed as follows:

- Service improvements, which can include the implementation of an integrated data sharing platform between manufacturer and customer 
- Product-development programs, including research and development activities, also introduction of new technologies to improve the quality of product and manufacturing process. Developing distinguished features of the product is important to deal with threat from substitute products.

- Efficiency improvement, which may be obtained by purchasing new equipment

- Labor skill development through some training programs

- Financial support in order to assist the production process and obtain customer's trust related with completion of the shipbuilding process

- Addition of labors, as faced by South Korea between 2006 and 2007, which enables the construction completion of a huge number of ships

Additional strategies may be:

- Searching for appropriate subcontractor that can provide a good product processing output or transportation service of raw materials within an acceptable time and cost

- Adding more suppliers in the supply chain in order to increase the flexibility of the manufacturer and discover raw material with lower prices. Searching for low-cost materials can provide a huge reduction of the shipbuilding cost, based on the cost factor information shown by Figure 2

- Labor wage reduction. It is reported that the labor cost is a huge part of the ship cost [7]. The labor wage mainly has an important role in competitions between shipbuilding manufacturers in different countries.

- Construction of new facilities, which fosters the shipbuilding industry growth in China [9]

- Merging and alliance with other shipbuilding manufacturers, which are effective to increase the company's competitiveness [9]

Some strategies can be implemented in a short time, such as product-development programs, while the others may require some in depth analysis as their effect may last for longer periods. Strategy selection in the next section can be performed while considering strategies that require similar implementation time periods, which may be distinguished based on the execution level of the strategies in strategic, tactical, or operational levels. On the other hand, strategies that require different implementation time lengths may also be considered in a same model, while considering that each strategy requires different level of resources, as long as the simultaneous consideration is approved in practice.

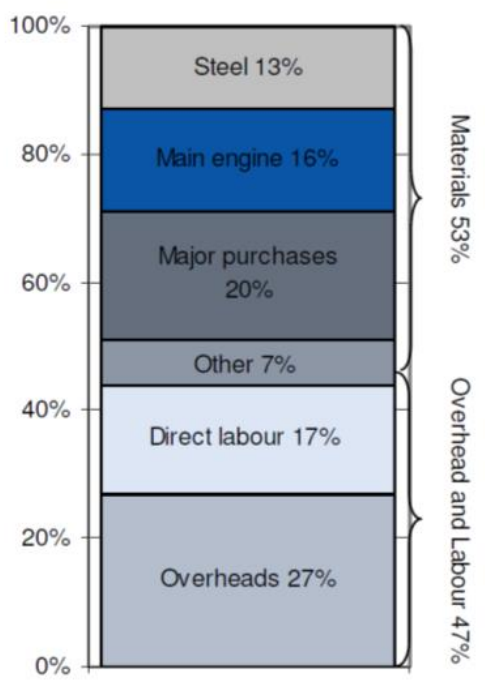

Figure 2: Cost factors of a shipbuilding product [3] 


\section{Mathematical Model Concept}

Basic product evaluation steps are introduced in [2], which are identifying the key buying factors, followed with the score assignment for the company's performance relative to the competitor's. In this study, more detailed steps are proposed as follows:

Step 1. Identify key product aspects.

Step 2. Define important competitors, which will be used for the evaluation process.

Step 3. Make a list of marketing or product development strategies, which are considered. Identify the effect of implementing each strategy to improve each product aspect.

Step 4. State the limit of available resources.

Step 5. Formulate and solve the mathematical model to select the best strategy.

In the proposed concept, the comparison can be performed with more than one competitor; even it may be possible to select only the toughest competitor for the benchmark. In Steps 3 and 4, the effect of implementing each strategy to improve each product aspect and the required amount of resources to execute each strategy can be defined based on historical data, which are justified by the experts. The lack of resources limits the execution of all strategies simultaneously. The resource itself may be time, cost, and effort. A single or multiple type(s) of resources may be considered.

A mathematical model is proposed for selecting the best marketing and product development strategy while performing comparison between the developer product and competitor's product quality. The model can be used considering the situation in which the product aspect need to be improved well relative to its competitor's considering existence the limited resources.

The sets, parameters, and decision variables of the model are: Sets:

I $\quad$ set of important product aspects

$J \quad$ set of important competitors (other companies)

$K \quad$ set of marketing and product development strategies

Parameters:

$a_{i j} \quad$ quality level for aspect $i$ of the product of company $j$

$b \quad$ available budget for marketing and product development

$c_{k} \quad$ cost required to execute marketing and production development $k$

$\max _{i} \quad$ maximum quality level possible for product aspect $i$

$m_{i k} \quad$ amount of quality level increase for product aspect $i$ by executing strategy $k$

$w_{i} \quad$ importance weight of product aspect $i$

$y_{i} \quad$ current quality level for aspect $i$ of the product that belongs to the current company

Decision variables:

$x_{k} \quad 1$, if marketing and product development $k$ are executed; 0, otherwise

Mathematical formulation:

$$
\begin{gathered}
\min \sum_{j \in J} \sum_{i \in I} w_{i}\left(a_{i j}-\left(y_{i}+\sum_{k \in K} x_{k} m_{i k}\right)\right) \\
\sum_{k \in K} x_{k} c_{k} \leq b \\
x_{k}=\{0,1\}, \quad \forall k \in K
\end{gathered}
$$

Objective function (1) minimizes the total product quality differences with the competitors and at the same time, maximizes the total quality of all developed product aspects. Weights given in the objective function are related with the importance of each product aspect. The importance level may be obtained through an initial assessment by gathering experts' knowledges using analytical 
hierarchy process, promethee, or other methods. Constraints (2) limit the total marketing and product development costs with the available budget. Constraints (3) are binary constraints.

Suppose that the manufacturer's main goal is to match the product quality provided by its competitor at any cost, the required improvement level of each product aspect may be set as the constraints and the strategy execution cost can be minimized in the objective function. This second model can be constructed as follows:

$$
\begin{gathered}
\sum_{k \in K} x_{k} c_{k} \\
y_{i}+\sum_{k \in K} x_{k} m_{i k} \geq a_{i j}, \quad \forall i \in I, j \in J \\
x_{k}=\{0,1\}, \quad \forall k \in K
\end{gathered}
$$

Objective function (4) minimizes the total costs required for executing all selected marketing and product development strategies. Constraints (5) assure that each developed product aspect is at least better than the quality of each product that belongs to each competitor. Constraints (6) are binary constraints.

More modifications on the model may be performed based on the current manufacturer's development plan. A typical example is shipbuilding manufacturers in China. Currently, Chinese shipbuilding industries in China have strong points in low-wages. However, producing outputs with acceptable quality is still a challenge for Chinese industries, which have been successfully implemented by leading Japanese and South Korean shipyards. Though requires some time, Chinese shipyards have achieved the product standard level requested by foreign customers [9] and took the first place as the world's largest shipbuilding nation in terms of new orders from South Korea at 2009 [1]. Meanwhile, South Korea can still be the best in producing high value-added ships. It can be seen that depending on the shipbuilding industry targets, different models may need to be applied.

\section{Conclusions}

In this study, important shipbuilding product aspects and related strategies for marketing and product development are addressed. A concept for a mathematical model is introduced in order to select appropriate strategy and increase the competitiveness of the shipbuilding manufacturer. Future researchers may attempt to address the relationship or interdependency between product aspects or strategies, in order to represent the real situation well. The situation, in which the competitor also improve its product aspects, can also be considered

\section{References}

[1] L. Jiang, E. Bastiansen, and S.P. Strandenes, "The international competitiveness of China's shipbuilding industry," Transportation Research Part E, vol. 60, pp. 39-48, September 2013.

[2] Customer Value, Inc., Marketing War Room, Release 6: Tools for Developing Value-based Strategies, Boston, 2013.

[3] S.M. Shaker, Lesson Learned from War Room Designs and Implementations. Vienna, 2002.

[4] McKinsey, McKinsey on Finance: Perspectives in Corporate Finance and Strategy. 2003.

[5] Accenture, Maximizing Value in the Mining Industry: New Approaches for A Volatile Environment. 2013.

[6] Center for Technology in Government, Information Sharing:Build A War Room. New York, 2003.

[7] ECORYS SCS Group, Study on Competitiveness of European Shipbuilding Industry. Rotterdam, 2009.

[8] K. Oy, Market Research on The Turkish Shipbuilding Industry. Finland: Lahti University of Applied Sciences, 2013. 
[9] K.A. Hossain, N.M.G. Zakaria, and M.A.R. Sarkar, "SWOT analysis of Chian shipbuilding industry by third eyes," Procedia Engineering, vol. 194, pp. 241-246, 2017 [10th International Conference on Marine Technology MARTEC, 2016]. 